\title{
Unlocking the potential with the use of check-point inhibitor immunotherapies in metastatic prostate cancer
}

\author{
Swaroop Revannasiddaiah, Ishu Gupta, Santhosh Kumar Devadas \\ Department of Medical Oncology, Ramaiah Medical College, Bengaluru, India \\ Correspondence to: Dr. Swaroop Revannasiddaiah. Department of Medical Oncology, Ramaiah Medical College, Bengaluru 560054, India. \\ Email: swarooptheone@gmail.com. \\ Comment on: Jindal V. Immunotherapy: a glimmer of hope for metastatic prostate cancer. Chin Clin Oncol 2018;7:61.
}

Submitted Jan 20, 2019. Accepted for publication Jan 24, 2019.

doi: $10.21037 /$ cco.2019.01.07

View this article at: http://dx.doi.org/10.21037/cco.2019.01.07

We have read the article published in this journal (December 2018) titled "Immunotherapy: a glimmer of hope for metastatic prostate cancer" with great interest (1). We wish to add on to the content of the article. The article being a comprehensive and well written review article focuses upon all aspects of immunotherapies in relation to prostate cancerranging from the use of anti-tumor vaccines, to the use of checkpoint inhibitors. We are of the opinion that future progress in the treatment of metastatic prostate cancer could be found in the combination of immune checkpoint inhibitor therapies with other modalities including chemotherapy, radiotherapy and hormonal therapy.

Metastatic prostate cancer is a malignancy which is often associated with prolonged survival, even if it is seldom curable. Effective therapies currently in vogue include hormonal therapy and chemotherapy, which offer varying durations of progression free survival before ultimately failing.

The advent of checkpoint inhibitors such as the PD-1 inhibitors (nivolumab, pembrolizumab) and PD-L1 inhibitors (atezolizumab, durvalumab) have shown early promise in metastatic prostate cancer (2).

We propose that checkpoint inhibitors in particular have a great potential in the treatment of metastatic prostate cancer due to the following reasons:

(I) Metastatic prostate cancer which has progressed after various lines of chemotherapy and radiotherapy is likely to have a high tumor mutational burden, thus rendering it sensitive to checkpoint targeting immunotherapies such as PD-1/PD-L1 inhibitors (3);

(II) The use of PD-1/PD-L1 inhibitors with focal irradiation is likely to elicit an abscopal effect leading to reduction in the overall tumour load (4).

Thus, we propose that research focussing upon the use of immune checkpoint inhibitors in the treatment of metastatic prostate cancer would be a worthwhile exercise, especially in the treatment of patients who are likely to high tumor mutational burden as a result of prior radiotherapy.

\section{Acknowledgments}

None.

\section{Footnote}

Conflicts of Interest: The authors have no conflicts of interest to declare.

\section{References}

1. Jindal V. Immunotherapy: a glimmer of hope for metastatic prostate cancer. Chin Clin Oncol 2018;7:61.

2. Comiskey MC, Dallos MC, Drake CG. Immunotherapy in Prostate Cancer: Teaching an Old Dog New Tricks. Curr Oncol Rep 2018;20:75.

3. Giordano FA, Veldwijk MR, Herskind C, et al. Radiotherapy, tumor mutational burden, and immune 
Page 2 of 2

checkpoint inhibitors: time to do the math. Strahlenther Onkol 2018;194:873-5.

4. Rodríguez-Ruiz ME, Vanpouille-Box C, Melero I,

Cite this article as: Revannasiddaiah S, Gupta I, Devadas SK. Unlocking the potential with the use of check-point inhibitor immunotherapies in metastatic prostate cancer. Chin Clin Oncol 2019;8(Suppl 1):S13. doi: 10.21037/cco.2019.01.07
Revannasiddaiah et al. Checkpoint inhibitors and prostate cancer

et al. Immunological Mechanisms Responsible for Radiation-Induced Abscopal Effect. Trends Immunol 2018;39:644-55. 